\title{
Densidades populacionais de milho em arranjos espaciais convencional e equidistante entre plantas
}

\author{
Maize plant densities in conventional and equidistant plant spacing
}

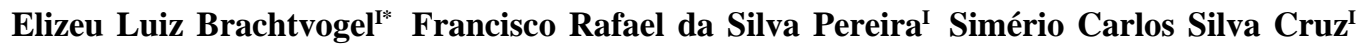 \\ Sílvio José Bicudo
}

\section{RESUMO}

A otimização da exploração do ambiente é necessária para a maximização do rendimento do milho. $O$ arranjo de plantas (distribuição espacial e área ocupada pela planta) interage diretamente na competição intraespecífica por fatores do meio. Assim, o objetivo deste trabalho foi comparar as formas de distribuição espacial equidistante entre plantas de milho e o espaçamento de 0,80 metro na entrelinha, em populações de 30000 a 105000 plantas ha ${ }^{-1}$. O experimento foi conduzido em área de Nitossolo Vermelho distroférrico, de textura argilosa, em Botucatu (SP), na safra 2007/08. O delineamento experimental foi o de blocos casualizados, e os tratamentos foram combinados em fatorial $2 X 6$ (quatro repetições), em parcelas de 4,5 x 10m. Foram avaliados os caracteres comprimento e diâmetro de espiga e sabugo, comprimento do grão; número de fileiras, massa e número de grãos por espiga, porcentagem de plantas acamadas; número de grãos e de espigas por hectare, índice de espiga, massa de mil grãos e produtividade. Todos os parâmetros avaliados foram influenciados pelas populações e a porcentagem de plantas acamadas pelos arranjos espaciais, com interação para o diâmetro de espiga e de sabugo. De maneira geral, pode-se concluir que as características avaliadas são influenciadas predominantemente pelas densidades populacionais, independentemente do arranjo espacial.

Palavras-chave: espaçamento entrelinhas, densidade de plantas, ecofisiologia, componentes de produção, fitotecnia, Zea mays.

\section{ABSTRACT}

The maximization of environmental resources exploration is necessary to maximize maize grain yield. The plant arrangement (spatial arrangement and occupied area by the plant), acts on the intraspecific competition by environmental factors. Thus, the objective of this work was to compare the equidistant plant spacing and $0.80 \mathrm{~m}$ row width, in populations of 30000 to 105000 plants $\mathrm{ha}^{-1}$. The essay was located in a clay red alfisol area, in the FCA/UNESP-Botucatu$S P$, in 2007/08 growing season. The experimental design was a randomized block in four replications, in $4.5 \times 10 \mathrm{~m}$ plots. It was evaluated ear and grain length, ear and cob diameter, number of grain rows and grain weight per ear, a thousand grains weight, ear index, ear and grain number per hectare, plant lodging and grain yield. All parameters evaluated were affected by plant densities and the spatial arrangements affected only the percentage of stalk lodged plants. In these conditions, it can be affirmed that the maize plant was influenced mainly by plant densities, not by plant arrangement.

Key words: row width, plant density, ecophysiology, production components, crop science, Zea mays.

\section{INTRODUÇÃO}

O arranjo de plantas pode ser manipulado por meio de alterações na densidade de plantas, no espaçamento entrelinhas e na distribuição de plantas na linha, e as variações na distância entre plantas na linha e nas entrelinhas conferem os diferentes arranjos espaciais na lavoura (ARGENTA et al., 2001a).

Teoricamente, o melhor arranjo é aquele que proporciona distribuição mais uniforme de plantas por área, possibilitando melhor utilização de luz, água e nutrientes. Idealmente, plantas espaçadas equidistantemente competem minimamente por nutrientes, luz e outros fatores de crescimento (LAÜER, 1994). De acordo com BULLOCK et al. (1988), modelos

IPrograma de Pós-Graduação graduação em Agronomia/Agricultura, Departamento de Produção Vegetal, Faculdade de Ciências Agronômicas (FCA), Universidade Estadual Paulista (UNESP), CP 237, 18603-970, Botucatu, SP, Brasil. E-mail: elizeub@fca.unesp.br.*Autor para correspondência. 
de distribuição mais favoráveis em virtude do uso de espaçamentos reduzidos aumentam a taxa de crescimento inicial da cultura, levando a uma melhor interceptação da radiação solar e uma maior eficiência no uso dessa radiação e resultando em maiores produtividades de grãos devido ao aumento da produção fotossintética líquida.

Dentre as formas existentes de manejo do arranjo espacial, a densidade de plantas é a que tem maior interferência na produção de milho, já que pequenas alterações na população implicam modificações relativamente grandes no rendimento de grãos. Essa resposta está associada ao fato de que a espécie Zea mays (L.) não possui um mecanismo de compensação de espaços tão eficiente quanto o mecanismo de outras espécies da família Poaceae, pois raramente perfilha efetivamente, e por apresentar capacidade limitada de expansão foliar e prolificidade (ANDRADE et al., 1999). O aumento da população de plantas, apesar de proporcionar ganhos de produtividade, geralmente afeta negativamente os componentes da produção (DOURADO NETO et al., 2003), independentemente do ciclo do híbrido (FLESCH \& VIEIRA, 2004).

Portanto, a escolha do arranjo de plantas adequado é uma prática de manejo importante para otimizar o rendimento de grãos de milho. Assim, o objetivo deste trabalho foi analisar a resposta de diferentes densidades populacionais na cultura do milho em arranjos espaciais convencional e equidistante entre plantas.

\section{MATERIAL E MÉTODOS}

O experimento foi conduzido na Fazenda de Ensino, Pesquisa e Produção Lageado da Faculdade de Ciências Agronômicas - FCA/UNESP, Campus de Botucatu, localizada pelas coordenadas geográficas $22^{\circ}$ $49^{\prime}$ 'S e $48^{\circ} 25^{\prime} \mathrm{W}$, altitude de $770 \mathrm{~m}$, em área cujo solo foi classificado como Nitossolo Vermelho distroférrico, de textura argilosa (EMBRAPA, 1999). O clima da região é, segundo a caracterização de Köeppen, do tipo Cwa, tropical úmido, com inverno seco (junho a agosto) e verão chuvoso (dezembro a fevereiro).

Antes da instalação do experimento, realizou-se coleta de amostra de solo para análise química conforme metodologia descrita por RAIJ et al. (1996), cujos resultados foram: $\mathrm{pH}$ em $\mathrm{CaCl}_{2}=5,1$; M.O. = $24 \mathrm{~g} \mathrm{dm}^{-3} ; \mathrm{P}$ (resina) $=18 \mathrm{mg} \mathrm{dm}^{-3} ; \mathrm{Al}^{3+}, \mathrm{H}+\mathrm{Al}, \mathrm{K}, \mathrm{Ca}, \mathrm{Mg}$, SB e CTC = 1; 38; 2,7; 31; 14; 48 e 85 $\mathrm{mmol}_{\mathrm{c}} \mathrm{dm}^{-3} \mathrm{e}, \mathrm{V}=$ $56 \%$. A calagem, realizada dois meses antes da semeadura com posterior aração e gradagem, assim como as adubações, foram realizadas conforme critérios preestabelecidos em RAIJ et al. (1996).
Foram testadas seis populações de plantas de milho híbrido simples DOW 2B587 combinadas em duas formas de arranjo espacial de plantas, totalizando 12 tratamentos. As populações de plantas utilizadas foram as de 30.000, 45.000, 60.000, 75.000, 90.000 e 105.000 plantas ha $^{-1}$, e as formas de arranjo espacial de plantas empregadas foram o espaçamento entrelinhas $0,80 \mathrm{~m}$, preconizado como o convencionalmente utilizado, e o arranjo espacial equidistante entre plantas. No arranjo espacial equidistante entre plantas, as distâncias entre plantas foram iguais na linha e entrelinha, as quais foram obtidas efetuando-se a raiz quadrada da área destinada a cada planta nas respectivas populações. O delineamento experimental utilizado foi de blocos casualizados, com quatro repetições, e os tratamentos foram aplicados em parcelas de 4,5 x 10m.

Os tratamentos foram instalados em semeadura convencional, com sulcagem por um sistema adaptado com "asa de andorinha”. As distribuições das sementes e do fertilizante (300kg ha-1 da fórmula $\mathrm{N}-\mathrm{P}_{2} \mathrm{O}_{5}-\mathrm{K}_{2} \mathrm{O}$ 08-28-16) foram feitas manualmente em 04/12/2007. A emergência das plântulas ocorreu no dia 10/12/2008.

O controle de plantas invasoras foi realizado por meio de aplicação de herbicida em pós-emergência com o ingrediente ativo Nicosulfuron, na dose de $16 \mathrm{~g}$ ha $^{-1}$ de i.a., e Atrazina, na dose de 1250 g ha $^{-1}$ de i.a., 10 dias após a emergência das plântulas. Para controle da lagarta do cartucho (Spodoptera frugiperda), foi utilizado um produto formulado à base do ingrediente ativo Espinosade, na dose de $25 \mathrm{~g} \mathrm{ha}{ }^{-1}$. Em ambas as aplicações, foi empregado pulverizador do tipo tratorizado, com volume de calda de 200L ha-1. As adubações nitrogenada e potássica em cobertura, tendo como fontes o sulfato de amônio e o cloreto de potássio, nas doses de $120 \mathrm{~kg} \mathrm{~N}^{-1}$ e $40 \mathrm{~kg} \mathrm{~K}_{2} \mathrm{O} \mathrm{ha}{ }^{-1}$, respectivamente, foram realizadas em 03/01/2008, quando as plantas apresentavam seis folhas totalmente desdobradas, conforme RAIJ et al. (1996).

Foram avaliados os caracteres comprimento (CE) (cm) e diâmetro de espiga (DE) e do sabugo (DS), comprimento do grão (CG) (mm), tomados com auxílio de régua e paquímetro digital, número de fileiras de grãos (NF) massa de grãos por espiga (MGE) (g), número de grãos por espiga (NGE), porcentagem de plantas acamadas (\% PA), número de grãos por hectare (NGH), número de espigas por hectare (NEH), índice de espiga (IE), massa de mil grãos (1.000G) (g) e produtividade $(\mathrm{P})\left(\mathrm{kg} \mathrm{ha}^{-1}\right)$, medidos por meio de balança digital com precisão de $0,001 \mathrm{~g}$.

Os dados foram submetidos à análise de variância pelo teste F. Quando constatada interação 
entre os fatores avaliados, procedeu-se ao desdobramento do fator população para cada arranjo espacial de plantas. Caso contrário, se significativo, procedeu-se ao teste de média para arranjo espacial de plantas e para populações à análise de regressão, calculada para equações lineares e quadráticas e consideradas significativas a $5\left(^{*}\right) \%$ de probabilidade pelo teste F. Quando ambas apresentaram significância, foi feita a opção por aquela com maior coeficiente de determinação $\left(\mathrm{R}^{2}\right)$.

\section{RESULTADOS E DISCUSSÃO}

Os resultados da análise de variância referentes aos caracteres morfológicos avaliados são apresentados nas tabelas 1 e 2 , com os valores de F calculados para as causas de variação, bem como o desdobramento dos graus de liberdade para as populações e as médias dos arranjos populacionais já incluídas.

Para a característica comprimento de espiga, pela análise de variância observou-se efeito apenas de população, conforme se verifica na tabela 1 . Fica evidente a progressiva redução no comprimento de espigas em função do aumento da população (Tabela 3), caracterizando aumento da competição intraespecífica. O presente estudo concorda também com os resultados obtidos por DOURADO NETO et al. (2003), os quais observaram redução no comprimento de espiga pelo aumento na população de plantas, devido, provavelmente, ao aumento da competição intraespecífica por água, nutrientes e luminosidade.

Para os dados de diâmetro de espiga e sabugo, observa-se, na análise de variância, interação entre os fatores testados (Tabela 1), havendo comportamento diferenciado dos níveis de população dentro de cada arranjo (Tabela 3). Em relação às populações testadas, com o aumento da população de plantas, o diâmetro da espiga e do sabugo decresceram, juntamente com o comprimento do grão e o número médio de fileiras de grãos por espiga (Tabela 1). A exemplo do que ocorreu com os diâmetros de espiga e de sabugo, o comprimento do grão e o número médio de fileiras de grãos por espiga reduziram linearmente à medida que se elevou a densidade de plantas (Tabela 3 ), sem contudo apresentar interação entre os fatores testados. Os dados obtidos demonstram claramente o efeito da competição intraespecífica sobre a espiga, pois, à medida que se aumenta a densidade de plantas, menos recursos do meio estão disponíveis para cada planta, refletindo diretamente em espigas menores.

Quanto à massa e ao número de grãos por espiga, a análise de variância demonstrou haver efeito apenas das populações estudadas, a qual se ajustou melhor ao modelo de regressão polinomial quadrático (maior $\mathrm{R}^{2}$ ) (Tabela 1 ). Apesar do decréscimo praticamente linear da massa de grãos por espiga com o aumento da população, o número máximo de grãos por espiga estimado foi de 507 em 49906 plantas ha-1 (Tabela 3). Esse comportamento é relatado com certa frequência na literatura (DOURADO NETO et al., 2003; PIANA et al., 2008), independentemente do híbrido (FLESCH \& VIEIRA, 2004; SANGOI et al., 2005; PIANA et al., 2008) e do espaçamento entrelinhas (DOURADO NETO et al., 2003), corroborando os resultados do presente estudo. Assim, cabe ressaltar a importância da competição intraespecífica com aumento da densidade populacional, pois, com menos recursos disponíveis, a planta produz espigas menores, com

Tabela 1 - Resumo da análise de variância de comprimento (CE), diâmetro de espiga (DE) e sabugo (DS), comprimento do grão (CG), número de fileiras (NF), massa (MGE) e número de grãos por espiga (NGE) em milho híbrido DOW2B587, safra 2007/08.

\begin{tabular}{|c|c|c|c|c|c|c|c|}
\hline \multirow{2}{*}{ Causas de Variação } & \multicolumn{7}{|c|}{ 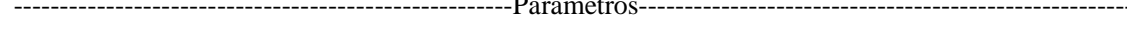 } \\
\hline & CE & $\mathrm{DE}$ & DS & CG & NF & MGE & NGE \\
\hline Bloco & $0,858^{\mathrm{NS}(1)}$ & $3,032 *$ & $5,505 *$ & $2,792^{\mathrm{NS}}$ & $0,679^{\mathrm{NS}}$ & $2,196^{\mathrm{NS}}$ & $1,082^{\mathrm{NS}}$ \\
\hline População (P) & $21480 *$ & $34,205^{*}$ & $37,518^{*}$ & $13,037 *$ & $6,472 *$ & $28,509 *$ & $9,463^{*}$ \\
\hline Modelo ${ }^{(2)}$ & $\mathrm{Q}^{*}$ & - & - & $\mathrm{L}^{*}$ & $\mathrm{~L}^{*}$ & $\mathrm{Q}^{*}$ & $\mathrm{Q}^{*}$ \\
\hline Arranjo (A) & $0,168^{\mathrm{NS}}$ & $0,001^{\mathrm{NS}}$ & $0,560^{\mathrm{NS}}$ & $0,139^{\mathrm{NS}}$ & $2,771^{\mathrm{NS}}$ & $0,044^{\mathrm{NS}}$ & $0,976^{\mathrm{NS}}$ \\
\hline Convencional & 15,1 & 49,71 & 25,78 & 11,97 & 15,5 & 153,87 & 471,46 \\
\hline Equidistante & 15,2 & 49,72 & 25,87 & 11,92 & 15,6 & 154,76 & 481,45 \\
\hline $\mathrm{P} \times \mathrm{A}$ & $0,979^{\mathrm{NS}}$ & $2,723^{*}$ & $5,642 *$ & $1,176^{\mathrm{NS}}$ & $2,194^{\mathrm{NS}}$ & $1,118^{\mathrm{NS}}$ & $1,236^{\mathrm{NS}}$ \\
\hline Média & 15,1 & 49,71 & 25,82 & 11,95 & 15,5 & 154,32 & 476,46 \\
\hline CV (\%) & 5,12 & 1,97 & 1,75 & 3,43 & 2,45 & 9,54 & 7,35 \\
\hline $\mathrm{R}^{2}$ & 0,9324 & - & - & 0,9893 & 0,6816 & 0,9829 & 0,9645 \\
\hline
\end{tabular}

${ }^{(1)}$ NS: não significativo *: significativo a 5\% de probabilidade de erro. ${ }^{(2)}$ L: equação linear, Q: equação quadrática. 
Tabela 2 - Resumo da análise de variância de plantas acamadas (\% PA), número de grãos (NGH) e de espigas por hectare (NEH), índice de espiga (IE), massa de mil grãos (1000G) e produtividade (P) em milho híbrido DOW 2B587, safra 2007/08.

\begin{tabular}{|c|c|c|c|c|c|c|}
\hline \multirow{2}{*}{ Causas de Variação } & \multicolumn{6}{|c|}{ 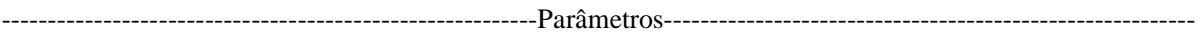 } \\
\hline & $\% \mathrm{PA}$ & NGH & NEH & IE & $1000 \mathrm{G}$ & $\mathrm{P}$ \\
\hline Bloco & $1,071^{\mathrm{NS}(1)}$ & $0,670^{\mathrm{NS}}$ & $0,473^{\mathrm{NS}}$ & $0,401^{\mathrm{NS}}$ & $3,809 *$ & $2,321^{\mathrm{NS}}$ \\
\hline População (P) & $46,718 *$ & $8,334 *$ & $19,394 *$ & $144,290 *$ & $28,105^{*}$ & $3,491 *$ \\
\hline Modelo ${ }^{(3)}$ & $\mathrm{Q}^{*}$ & $\mathrm{Q}^{*}$ & $\mathrm{~L}^{*}$ & $\mathrm{Q}^{*}$ & $\mathrm{~L}^{*}$ & $\mathrm{Q}^{*}$ \\
\hline Arranjo (A) & $4,896^{*}$ & $3,294^{\mathrm{NS}}$ & $1,716^{\mathrm{NS}}$ & $3,683^{\mathrm{NS}}$ & $1,472^{\mathrm{NS}}$ & $1,655^{\mathrm{NS}}$ \\
\hline Convencional & $20,49 b^{(2)}$ & 34006,8 & 72708,3 & 1,22 & 325,38 & 11031,90 \\
\hline Equidistante & 27,46 a & 35959,1 & 75575,3 & 1,27 & 318,46 & 11669,90 \\
\hline $\mathrm{P} \times \mathrm{A}$ & $1,171^{\mathrm{NS}}$ & $0,389^{\mathrm{NS}}$ & $0,392^{\mathrm{NS}}$ & $0,486^{\mathrm{NS}}$ & $0,754^{\mathrm{NS}}$ & $0,523^{\mathrm{NS}}$ \\
\hline Média & 23,97 & 34983,0 & 74141,8 & 1,25 & 321,92 & 11350,9 \\
\hline CV (\%) & 45,49 & 10,65 & 10,23 & 7,51 & 6,14 & 15,13 \\
\hline $\mathrm{R}^{2}$ & 0,9745 & 0,9390 & 0,9869 & 0,9926 & 0,9534 & 0,9454 \\
\hline
\end{tabular}

${ }^{(1)}$ NS: não significativo *: $\mathrm{P}<0,05 .{ }^{(2)}$ Médias na vertical diferem pelo teste Tukey, a $5 \%$ de significância. ${ }^{(3)}$ L: equação linear, Q: equação quadrática.

menos grãos e grãos mais leves, acarretando menor produção por planta. No entanto, SANGOI et al. (2001a) reportam aumento do número de grãos por espiga com a diminuição do espaçamento entrelinhas, contrariando os resultados obtidos.

A porcentagem de plantas acamadas e/ou quebradas foi influenciada pelas populações e pelos arranjos espaciais de plantas testadas, mas não houve interação dos fatores testados (Tabela 2). Verifica-se um incremento acentuado da porcentagem de plantas acamadas e quebradas com o aumento da população (Tabela 3), bem como do arranjo espacial de plantas equidistante, comparado ao convencional (Tabela 2). $\mathrm{O}$ aumento do acamamento/ quebramento de colmo com aumento da população relatado no presente estudo também foi relatado por SANGOI et al. (2002c) e está ligado principalmente à diminuição do diâmetro do colmo, ao aumento da altura de planta e de inserção de espiga e ao aumento da relação altura de planta/ altura de inserção de espiga, observados quando elevase a população de plantas.

O índice de espigas e o número de espigas por hectare foram influenciados apenas pelas populações de plantas (Tabelas 2 e 3). Apesar do

Tabela 3 - Equações de regressão para as características avaliadas em função de populações de plantas de milho híbrido DOW 2B587, safra $2007 / 08$.

\begin{tabular}{|c|c|c|c|c|}
\hline Parâmetros & Equação de regressão & $\mathrm{R}^{2}$ & x máx $\min ^{-1}$ & y máx $\min ^{-1}$ \\
\hline $\mathrm{CE}$ & $y=16,281+2 E^{-05} x-5 E^{-10} x^{2}$ & $0,9843^{*(1)}$ & $30000^{(2)}$ & 16,45 \\
\hline DEeq & $y=55,510-9 E^{-05} x$ & $0,9498 *$ & $30000^{(2)}$ & 52,94 \\
\hline DEconv & $y=53,607-6 E^{-05} x$ & $0,9504 *$ & $30000^{(2)}$ & 51,88 \\
\hline DSeq & $y=28,604-4 E^{-05} x$ & $0,8796 *$ & $30000^{(2)}$ & 27,39 \\
\hline DSconv & $y=27,712-3 E^{-05} x$ & $0,8620^{*}$ & $30000^{(2)}$ & 26,85 \\
\hline CG & $y=13,202-2 E^{-05} x$ & 0,9893* & $30000^{(2)}$ & 12,64 \\
\hline NF & $\mathrm{y}=16,256-1 \mathrm{E}^{-05} \mathrm{x}$ & $0,6816^{*}$ & $30000^{(2)}$ & 15,95 \\
\hline MGE & $y=181,09+0,0004 x-1 E^{-08} x^{2}$ & $0,9829 *$ & $30000^{(2)}$ & 182,97 \\
\hline NGE & $y=427,40+0,0032 x-3 E^{-08} x^{2}$ & $0,9645 *$ & $49906^{(2)}$ & 507,53 \\
\hline$\%$ PA & $y=-0,8082+3 E^{-05} x+5 E^{-10} x^{2}$ & $0,9745^{*}$ & $105000^{(2)}$ & 3,30 \\
\hline NGH & $y=14327+0,5711 x-3 E^{-06} x^{2}$ & $0,9390 *$ & $83178^{(2)}$ & 38080,01 \\
\hline $\mathrm{NEH}$ & $y=45935+0,4179 x$ & $0,9869 *$ & $105000^{(2)}$ & 89812,02 \\
\hline IE & $y=2,9324-4 E^{-05} x+2 E^{-10} x^{2}$ & $0,9926 *$ & $101678^{(3)}$ & 0,89 \\
\hline $1000 \mathrm{G}$ & $y=408,87-0,0013 x$ & $0,9534 *$ & $30000^{(2)}$ & 370,23 \\
\hline $\mathrm{P}$ & $y=4436,5+0,2409 x-2 E^{-06} x^{2}$ & $0,9454 *$ & $67167^{(2)}$ & 12528,21 \\
\hline
\end{tabular}

(1) *:significativo a 5\% de probabilidade de erro. ${ }^{(2)}$ x e y máximo estimado. ${ }^{(3)}$ x e y mínimo estimado. 
decréscimo do índice de espiga com o aumento da população de plantas, o número de espigas por hectare aumentou, pois a redução no índice de espiga observada, ao redor de 1,0 espiga por planta ou $50 \%$, foi menor que o aumento da população promovido, cerca de 3,5 vezes, promovendo assim acréscimos no número final de espigas. Aumentos semelhantes no número de espigas por área com aumento da população de plantas foram reportados por PIANA et al. (2008), trabalhando com mesmo híbrido em condições de semeadura precoce no Rio Grande do Sul.

Esse aspecto relatado no presente estudo confirma o comportamento encontrado em alguns trabalhos, em que, apesar de ocorrerem ganhos de produtividade com o aumento da população de plantas, normalmente os componentes da produção massa de mil grãos, número de grãos por espiga e número de espigas por planta são afetados negativamente (DOURADO NETO et al., 2003), independentemente do ciclo do híbrido (FLESCH \& VIEIRA, 2004), e que possivelmente está associada ao aumento na competição intraespecífica (SANGOI, 2001b).

Outros autores também encontraram redução nesses componentes da produção com o aumento da população de plantas de 50.000 plantas ha ${ }^{-1}$ para 65000 plantas ha ${ }^{-1}$ (ARGENTA et al., 2001b) e 50000 plantas ha-1 até 90000 plantas (FLESCH \& VIEIRA, 2004), relatando que tais perdas foram compensadas por um maior número de plantas, consequentemente, por um maior número de espigas por área, pois a produtividade de grãos não foi afetada, concordando com os resultados obtidos no presente estudo. Segundo esses autores, em lavouras com alta população de plantas e sob boas condições de crescimento, as espigas adicionais resultarão em maior produtividade de grãos, por maximizar o número de grãos por área. Porém, essa compensação ocorre até que o maior número de espigas por área não é mais suficiente para compensar a redução do número e da massa dos grãos (DOURADO NETO et al., 2003).

$\mathrm{O}$ índice de espiga ou prolificidade é um importante indicativo da capacidade dos híbridos modernos em suportar maiores populações, sem diminuir muito a emissão e manutenção das espigas. No presente estudo, houve decréscimo do número de espigas por planta à medida que se elevou a população de plantas. Dados semelhantes foram encontrados por ARGENTA et al. (2001b) e FLESCH \& VIEIRA(2004), os quais também trabalharam com diferentes híbridos e obtiveram redução do índice de prolificidade com o aumento da população de plantas. No presente estudo, não houve diferença para o índice de espiga entre os arranjos (Tabela 2). Outros autores, trabalhando com diferentes híbridos em diferentes locais e anos, também não encontraram variação do índice de espiga com a redução do espaçamento (ARGENTA et al., 2001b; SANGOI et al., 2001a; DOURADO NETO et al., 2003; FLESCH\& VIEIRA, 2004).

Para o número de grãos produzido por hectare, foi detectado efeito apenas das populações testadas (Tabela 2), obtendo-se um aumento quadrático do número de grãos por área com o aumento da população (Tabela 3), com máximo estimado de 38080 grãos ha-1 em 67167 plantas ha ${ }^{-1}$, o que concorda com os resultados de SANGOI et al. (2002b) e discorda de SANGOI et al. (2005), os quais relataram crescimento linear do número de grãos por área com ao aumento da população de plantas. Desse modo, comprova-se o efeito da competição intraespecífica no estabelescimento do número de grãos, pois, com o aumento da densidade populacional, há aumento do número de espigas e, consequentemente, aumento do número potencial de grãos por área. Contudo, a competição intraespecífica atua de modo que a menor disponibilidade de carbohidratos por unidade de grão na época de seu estabelescimento cause abortamento (RAJCAN \& TOLLENAAR, 1999) e, consequentemente, comportamento quadrático para a característica (DOURADO NETO et al., 2003).

Com relação à massa de mil grãos, por meio da análise de variância, observa-se efeito apenas das populações testadas (Tabela 2). A exemplo do que ocorreu com o comprimento do grão, a massa de mil grãos reduziu linearmente à medida que se elevou a densidade de plantas (Tabela 3), sem, contudo, apresentar interação entre população e formas de distribuição.

Outros autores também encontraram redução da massa de mil grãos com o aumento da população de plantas (DOURADO NETO et al., 2003; FLESCH \& VIEIRA, 2004; PIANA et al., 2008). Essa redução possivelmente está associada ao aumento da competição intraespecífica provocada pelo aumento da população de plantas (SANGOI, 2001b), pois a disponibilidade de carbohidratos por unidade de grão decresce linearmente com o aumento da população de plantas.

Para a produtividade de grãos, obteve-se influência somente das populações testadas (Tabela 2), vericando-se um padrão quadrático de produtividade com o aumento da população de plantas (Tabela 3), com produção máxima estimada de $12.528 \mathrm{~kg}$ ha $^{-1}$ em 67167 plantas ha- ${ }^{-1}$ O referido comportamento concorda com FLESCH \& VIEIRA (2004), em que foram testados quatro espaçamentos, quatro densidades populacionais e dois híbridos de ciclo contrastantes, e 
ambos os híbridos responderam de forma quadrática ao aumento da população de plantas, incrementando a produtividade de grãos a partir de 30.000 plantas até 70.000 plantas. ha ${ }^{-1}$ e diminuindo a 90.000 plantas ha $^{-1}$, independentemente do espaçamento utilizado.

\section{CONCLUSÕES}

Nas condições em que o experimento foi instalado e conduzido, pode-se concluir que as características avaliadas são influenciadas predominantemente pelas densidades populacionais, independentemente do arranjo espacial utilizado.

\section{AGRADECIMENTOS}

Ao Conselho Nacional de Desenvolvimento Científico e Tecnológico (CNPQ) e à Coordenação de Aperfeiçoamento de Pessoal de Nível Superior (CAPES), pelas bolsas de pós-graduação concedidas.

\section{REFERÊNCIAS}

ANDRADE, F.H. et al. Kernel number determination in maize. Crop Science, Madison, v.39, n.2, p.453-459, 1999. Disponível em: <http://crop.scijournals.org/cgi/reprint/39/2/ 453>. Acesso em: 10 jun. 2009.

ARGENTA, G. et al. Arranjo de plantas em milho: análise do estado-da-arte. Ciência Rural, Santa Maria, v.31, n.6, p.10751084, 2001a. Disponível em: <http://dx.doi.org/10.1590/S010384782001000600027>. Acesso em: 10 jun. 2009. doi:10.1590/ S0103-84782001000600027.

ARGENTA, G. et al. Resposta de híbridos simples à redução do espaçamento entrelinhas. Pesquisa Agropecuária Brasileira, Brasília, v.36, n.1, p.71-78, 2001b. Disponível em: <http:// dx.doi.org/10.1590/S0100-204X2001000100009>. Acesso em: 10 jun. 2009. doi: 10.1590/S0100-204X2001000100009.

BULLOCK, D.G. et al. A growth analysis comparison of corn grown in conventional and equidistant plant spacing. Crop Science, Madison, v.28, n.2, p.254-258, 1988. Disponível em: <http://crop.scijournals.org/cgi/reprint/28/2/254>. Acesso em: 10 jun. 2009

DOURADO NETO, D. et al. Efeito da população de plantas e do espaçamento sobre a produtividade de milho. Revista Brasileira de Milho e Sorgo, Sete Lagoas, v.2, n.3, p.63-77, 2003. Disponível em: <http://www.abms.org.br/revista/ revista_v2_n3/PDF/ARTIGO _06_durval.pdf>. Acesso em: 10 jun. 2009.

EMPRESA BRASILEIRA DE PESQUISA AGROPECUÁRIA Sistema brasileiro de classificação de solos. Brasília, 1999. 412 p.

FLESCH, R.D.; VIEIRA, L.C. Espaçamentos e densidades de milho com diferentes ciclos no oeste de Santa Catarina, Brasil. Ciência
Rural, Santa Maria, v.34, n.1, p.25-31, 2004. Disponível em: $<$ http://dx.doi.org/10.1590/S0103-84781997000400004>. Acesso em: 10 jun. 2009. doi:10.1590/S0103-84781997000400004.

LAÜER, J. Should 1 be planting corn at a 30-inch row spacing? Wisconsin Crop Manager, Madison, v.l, n.6, p.6-8, 1994. Disponível em: <http://corn.agronomy.wisc.edu/WCM/W001.aspx>. Acesso em: 10 jun. 2009.

PIANA, A.T. et al. Densidade de plantas de milho híbrido em semeadura precoce no Rio Grande do Sul. Ciência Rural, Santa Maria, v.38, n.9, p 2608-2612, 2008. Disponível em : <http:// dx.doi.org/10.1590/S0103-84782008005000023>. Acesso em: 15 mai. 2008. doi:10.1590/S0103-84782008005000023.

RAIJ, B. Van. et al. (Eds.) Recomendações de adubação e calagem para o Estado de São Paulo. 2.ed. Campinas: IAC, 1996. p.285. (Boletim técnico, 100).

RAJCAN, L.; TOLLENAAR, M. Source: sink ratio and leaf senescence in mayze. I. dry matter accumulation and partitioning durring grain filling. Field Crops Research, v.60, n. 1. p.245253, 1999. Disponível em: <http://dx.doi.org/10.1016/S03784290(98)00142-7>. Acesso em 10 jun. 2009. doi: 10.1016/ S0378-4290(98)00142-7.

SANGOI, L. et al. Rendimento de grãos, produção e distribuição de massa seca de híbridos de milho em função do aumento da densidade de plantas. Revista Brasileira de Agrociência, Pelotas, v.11, n.1, p.25-31, 2005. Disponível em: <http:// www.ufpel.tche.br/faem/agrociencia/v11n1/artigo04.pdf $>$. Acesso em: 10 jun. 2009.

SANGOI, L. et al. Bases morfofisiológicas para maior tolerância dos híbridos modernos de milho a altas densidades de plantas. Bragantia, Campinas, v.61, n.2, p.101-110. 2002a. Disponível em : <http:// dx.doi.org/10.1590/S0006-87052002000200003>. Acesso em: 10 jun. 2009. doi: 10.1590/S0006-87052002000200003.

SANGOI, L. et al. Response of Brazilian maize hybrids from different eras to changes in plant density. Field Crops Research, v.79, n.1, p.39-51, 2002b. Disponível em: <http:/ /dx.doi.org/10.1016/S0378-4290(02)00124-7>. Acesso em 10 jun. 2009. doi: 10.1016/S0378-4290(02)00124-7.

SANGOI, L. et al. Sustentabilidade do colmo em híbridos de milho de diferentes épocas de cultivo em função da densidade de plantas. Revista de Ciências Agroveterinárias, Lages, v.1, n.2, p.1, 2002c.

SANGOI, L. et al. Influence of row spacing reduction on maize grain yield in regions with a short summer. Pesquisa Agropecuária Brasileira, Brasília, v.36, n.6, p.861-869, 2001a. Disponível em: <http://dx.doi.org/10.1590/S0100204X2001000600003>. Acesso em: 10 jun. 2009. doi: 10.1590/S0100-204X2001000600003.

SANGOI, L. Understanding plant density effects on maize growth and development: an important issue to maximize grain yield. Ciência Rural, Santa Maria, v.31, n.1, p.159-168, 2001b. Disponível em: <http://dx.doi.org/10.1590/S010384782001000100027>. Acesso em: 25 ago. 2008. doi: 10.1590/S0103-84782001000100027. 